\title{
The Involvement of Protein Kinase D in T Cell-Induced Mast Cell Activation
}

\author{
Pazit Salamon Irit Shefler Alon Y. Hershko Yoseph A. Mekori \\ Laboratory of Allergy and Clinical Immunology, The Herbert Mast Cell Disorders Center, Meir Medical Center, \\ Kfar Saba, and Sackler School of Medicine, Tel Aviv University, Tel Aviv, Israel
}

\section{Keywords}

Heterotypic adhesion · Mast cells · T cells · Protein kinase D

\begin{abstract}
Background: It has recently been reported that mast cells (MC) can be activated to degranulate and release certain cytokines in response to direct physical contact with activated but not resting T cells or their membranes. The MAPK family members ERK and p38 were found to participate. In this work, we further characterize the signaling events involved in this novel pathway of activation. Methods: Human MC were stimulated by activated T cell membranes ( $\left.T^{*} \mathrm{~m}\right)$. Phosphorylation of kinases was assessed by Western blotting. Protein kinase $D(P K D)$ translocation was visualized by confocal microscopy. Degranulation was assessed by $\beta$-hexosaminidase release and cytokine production by ELISA. Results: Stimulation of human MC by activated $T^{*} \mathrm{~m}$ resulted in the activation of PKD. PKD inhibition by the specific pharmacological inhibitor Gö6976 resulted in a reduction in the phosphorylation of p38 but not ERK. Gö6976 also inhibited degranulation and cytokine release. Conclusions: MC stimulation by physical contact with T cells results in PKD activation, leading to the phosphorylation of p38, degranulation and release of cytokines. Understanding the molecular events associated with $\mathrm{T}$ cellinduced MC activation might lead to therapeutic approaches for controlling $\mathrm{T}$ cell-mediated inflammatory processes in which MC participate.

(c) 2017 S. Karger AG, Basel
\end{abstract}

\section{Introduction}

Mast cells (MC) are central effector cells in the elicitation of early- and late-phase allergic inflammatory reactions. The close physical proximity between MC and $\mathrm{T}$ cells seen in inflamed tissues has led investigators to propose a bidirectional interaction between these 2 cell populations [1]. We have previously shown that direct contact with activated but not resting $\mathrm{T}$ cells, or their membranes or microvesicles, resulted in MC degranulation and the production of various cytokines such as IL-8, oncostatin M (OSM) and IL-24 [1-4]. This pathway is also associated with the activation of ERK and p38 [5].

In this study, we further explored the signal transduction pathway of $\mathrm{T}$ cell-induced MC activation.

\section{Materials and Methods}

\section{Antibodies}

The following antibodies were used for this study: anti-total protein kinase D (PKD) and anti-phosphorylated PKD (S916) $\left(\right.$ Abcam $^{\circledR}$, Cambridge, UK), PKD/PKC $\mu$ (C-20) (Santa Cruz Biotechnology, Inc., Heidelberg, Germany), anti-phosphorylated p38 and ERK p44/42 (Cell Signaling Technology, Danvers, MA, USA), anti-tubulin (Sigma-Aldrich, St. Louis, MO, USA), HRP- and Alexa Fluor ${ }^{\circledR}$ 594-conjugated secondary antibodies (Jackson ImmunoResearch Laboratories, West Grove, PA, USA).

\section{KARGER}

(c) 2017 S. Karger AG, Basel

E-Mail karger@karger.com

www.karger.com/iaa
Correspondence to: Dr. Pazit Salamon

Laboratory of Allergy and Clinical Immunology

The Herbert Mast Cell Disorders Center, Meir Medical Center

Kfar Saba 4428164 (Israel)

E-Mail pazit.salamon@ @lalit.org.il 
Cells

Reagents for cell culture were purchased from Biological Industries (Beit Haemek, Israel). Jurkat T cell lymphoma cells were maintained in RPMI 1640 supplemented with 10\% FCS, 2 mM L-glutamine, $100 \mathrm{U} / \mathrm{mL}$ penicillin, $100 \mu \mathrm{g} / \mathrm{mL}$ streptomycin, and $12.5 \mathrm{U} / \mathrm{mL}$ nystatin. The human LAD2 MC were maintained in StemPro-34 ${ }^{\circledR}$ SFM (GIBCO ${ }^{\mathrm{TM}}$ Invitrogen Corp., Grand Island, NY, USA) supplemented with $2 \mathrm{~mm}$ L-glutamine, $50 \mu \mathrm{g} / \mathrm{mL}$ streptomycin, $100 \mathrm{IU} / \mathrm{mL}$ penicillin, and $100 \mathrm{ng} / \mathrm{mL}$ recombinant human stem cell factor (SCF, PeproTech Asia, Rehovot, Israel) as previously described [6]. Primary cultured human cord blood MC were derived from human cord blood mononuclear cells in the presence of SCF, IL-6, and prostaglandin $\mathrm{E}_{2}$, and used as previously described [4].

\section{Preparation of T Cell Membranes}

Jurkat $\mathrm{T}$ cell membranes were isolated by a method described previously [1]. Briefly, cells were either not activated, or activated with $75 \mathrm{ng} / \mathrm{mL}$ PMA (Calbiochem, San Diego, CA, USA) at $2 \times 10^{6} \%$ $\mathrm{mL}$ for $60 \mathrm{~min}$ at $37^{\circ} \mathrm{C}$. At the end of incubation, the cells were washed with PBS and resuspended in ice-cold TKMS lysis buffer, comprising $50 \mathrm{mM}$ Tris- $\mathrm{HCl}$ ( $\mathrm{pH} 7.4$ ), $25 \mathrm{mM} \mathrm{KCl}, 5 \mathrm{mM} \mathrm{MgCl}_{2}$, $0.25 \mathrm{M}$ sucrose, $1 \mathrm{mM}$ PMSF, and Complete ${ }^{\mathrm{TM}}$, a mixture of protease inhibitors (Roche Applied Science, Boehringer, Mannheim, Germany). The cells were kept on ice for $20 \mathrm{~min}$, and lysed by 5 cycles of freezing and thawing following centrifugation at $800 \mathrm{~g}$ for $5 \mathrm{~min}$ at $4^{\circ} \mathrm{C}$. The supernatants were collected and subjected to centrifugation at $100,000 \mathrm{~g}$ for $60 \mathrm{~min}$ at $4^{\circ} \mathrm{C}$. The pellets were suspended in PBS and stored at $-70^{\circ} \mathrm{C}$.

\section{Mast Cell Activation}

LAD2 cells $\left(5 \times 10^{5}\right)$ were untreated or incubated with $20 \mu \mathrm{g} /$ $\mathrm{mL}$ of activated $\left(\mathrm{T}^{*} \mathrm{~m}\right)$ or nonactivated (Tm) Jurkat T cell membranes, for the indicated time periods. For IgE-mediated activation, cells were sensitized overnight with $500 \mathrm{ng} / \mathrm{mL}$ human myeloma IgE (Calbiochem), washed, and then stimulated with $10 \mu \mathrm{g} /$ $\mathrm{mL}$ anti-human IgE (Dako, Glostrup, Denmark). In some experiments, various concentrations of the inhibitor Gö6976 (Calbiochem) were introduced to the LAD2 cells 30 min before the addition of stimulation. Cell viability was determined at the end of incubation period by Trypan blue staining. In all experiments, viability was found to be $>95 \%$.

\section{$\beta$-Hexosaminidase Release}

$\beta$-hexosaminidase release was determined by incubating $20-\mu \mathrm{L}$ aliquots of supernatants and cell lysates for $90 \mathrm{~min}$ at $37^{\circ} \mathrm{C}$ with 50 $\mu \mathrm{L}$ of substrate solution consisting of $1.3 \mathrm{mg} / \mathrm{mL}$-nitrophenyl-Nacetyl- $\beta$-D-glucosaminide (Sigma) in $0.1 \mathrm{M}$ citrate ( $\mathrm{pH} 4.5)$. Reactions were stopped by the addition of $150 \mu \mathrm{L}$ of $0.2 \mathrm{M}$ glycine $\mathrm{pH}$ 10.7. Optical density was read at $405 \mathrm{~nm}$. Results (mean \pm SE) are expressed as the percentage of total $\beta$-hexosaminidase activity present in the cells.

\section{Human Cytokine Assay}

Supernatants of activated MC, as indicated above, were examined for released CCL2/MCP-1 and OSM by using a commercial ELISA kit, according to the manufacturer's instructions (DuoSet; R\&D Systems, Minneapolis, MN, USA). IL-8 release was determined by using a commercial ELISA kit as per the manufacturer's instructions (development kit; PeproTech Asia).

\section{SDS-PAGE and Immunoblotting}

Cellular extracts were separated by SDS-PAGE with $10 \%$ polyacrylamide gels, transferred to PVDF filters, and processed for immunoblotting, as previously described [1]. Immunoreactive bands were visualized with the LAS-3000 imaging system (Fujifilm Corp., Tokyo, Japan).

\section{Immunofluorescence}

Cytospins of untreated $\mathrm{MC}$ or incubated with $\mathrm{T}^{*} \mathrm{~m}$ for the indicated time periods were fixed in $2 \%$ paraformaldehyde, permeabilized with $0.2 \%$ Triton X-100, blocked in $5.5 \%$ goat serum, and incubated with anti-PKD/PKC $\mu$ (Santa Cruz). Binding was detected by Alexa Fluor ${ }^{\circledR}$ 594-conjugated goat anti-rabbit fluorescent secondary antibody (Jackson ImmunoResearch Laboratories). Cells were analyzed by using a Leica TCS SP 5 confocal microscope (Leica Microsystems GmbH, Wetzlar, Germany).

\section{Statistical Analysis}

Results are presented as means \pm SE. Statistical analysis was performed with the paired Student $t$ test. $p \leq 0.05$ was considered statistically significant.

\section{Results}

\section{Stimulation of Human MC by $T^{*} m$ Leads to PKD} Activation

We have previously shown that stimulation of MC by $\mathrm{T}^{*} \mathrm{~m}$ leads to degranulation and release of certain cytokines [1-3], and is associated with the phosphorylation of ERK and p38 [5]. The PKD family has been implicated in diverse cellular functions [7]. Furthermore, PKD is activated in murine bone marrow-derived MC (BMMC) stimulated through TLR2, Kit, or FceRI [8]. Based on these observations, and in order to further explore the downstream events associated with $\mathrm{T}$ cell-induced MC activation, LAD2 MC were incubated with Tm or T*m, and the cell extracts were analyzed for PKD activation. Tm induced a low level of PKD phosphorylation (Fig. 1a, left panels). In contrast, stimulation of LAD2 cells by T*m induced high levels of PKD phosphorylation within $5 \mathrm{~min}$, to a constant level over time, as shown by densitometry (Fig. 1b, left panel). Stimulation of MC with specific IgE and antigen also resulted in the phosphorylation of PKD, peaking within $5 \mathrm{~min}$, but declining over time (Fig. 1a, b, right panels). The expression of PKD was also analyzed in mature (aged 9-10 weeks) human cord blood-derived primary MC (CBMC). A marked increase in PKD phosphorylation was observed in response to the incubation of these primary $\mathrm{MC}$ with $\mathrm{T}^{*} \mathrm{~m}$ but not with Tm (Fig. 1c), thus supporting the validity of LAD2 as a human MC model.

PKD has been shown to translocate from the cytosol to the plasma membrane following antigen receptor stim- 
Fig. 1. $\mathrm{PKD}$ expression and activation in human MC. a LAD2 cells were untreated (med) or stimulated for the indicated time periods with $\mathrm{Tm}, \mathrm{T}^{*} \mathrm{~m}$, or by cross-linking the FceRI (IgE + Ag). The pPKD levels were analyzed by immunoblotting. b Densitometry of pPKD in T*m- or FceRI cross-linking-stimulated LAD2 cells. c PKD phosphorylation in human CBMC incubated with either Tm or $\mathrm{T}^{*} \mathrm{~m}$ for $5 \mathrm{~min}$. d Immunofluorescence staining of PKD in untreated, Tm- or T*m-stimulated LAD2 cells. Representative results from 3 independent experiments are shown. OD, optical density.

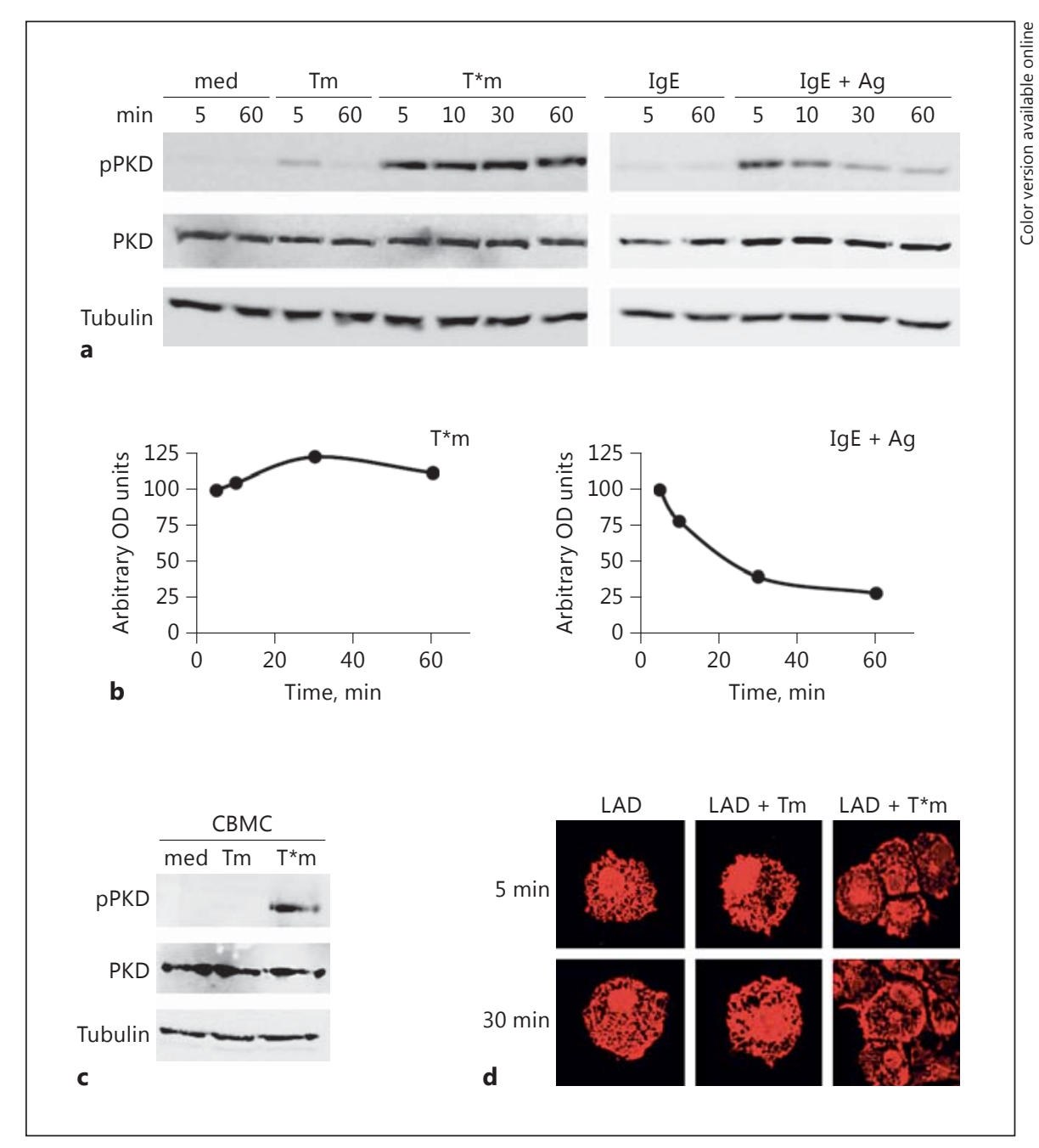

ulation in the RBL $2 \mathrm{H} 3$ cell line [9]. Therefore, we investigated the localization of PKD in LAD2 cells. In resting $\mathrm{MC}$ and Tm-stimulated MC, the confocal images revealed that PKD is distributed in the cytoplasm (Fig. 1d, left and middle panels) whereas in $\mathrm{T}^{*} \mathrm{~m}$-stimulated cells, it was partially translocated to the plasma membrane (Fig. 1d, right panel). This could be observed within 5-30 min of stimulation.

\section{PKD Inhibition Affects p38 in $T^{*} m$-Activated Human}

\section{$M C$}

It has previously been shown that the PKD family is involved in the activation of MAPK [7]. We therefore investigated whether PKD is involved in p38 and ERK phosphorylation in $\mathrm{T}^{*} \mathrm{~m}$-activated human MC. By using Gö6976, a PKD inhibitor [10], introduced to LAD2 cells $30 \mathrm{~min}$ prior to the addition of $\mathrm{T}^{*} \mathrm{~m}$, we could inhibit
PKD and p38 phosphorylation in a dose-dependent manner, while ERK phosphorylation was not affected (Fig. 2a, b). In contrast, the phosphorylation of both p38 and ERK was inhibited dose-dependently by Gö6976 in MC activated via FceRI-cross-linking (Fig. 2c, d).

\section{PKD Involvement in Degranulation and Cytokine \\ Release by $\mathrm{T}^{*} \mathrm{~m}$-Activated Human MC}

$\mathrm{PKD}$ activation was found to be related to degranulation and the increase in CCL2/MCP-1 expression and release by stimulated BMMC [8]. Hence, we thought to examine the involvement of PKD in degranulation and cytokine release by $\mathrm{T}^{*} \mathrm{~m}$-stimulated MC. We first analyzed whether the stimulation of LAD2 cells by $\mathrm{T}^{*} \mathrm{~m}$ would induce the release of this cytokine/chemokine as well. As presented in Figure 3a, activation of LAD2 cells by $\mathrm{T}^{*} \mathrm{~m}$ resulted in a 14-fold release of CCL2/MCP-1 (62 and 870 
Fig. 2. The involvement of PKD in MAPK activation. LAD2 cells were preincubated for $30 \mathrm{~min}$ with indicated concentrations of Gö6976. Subsequently, cells were either untreated (med) or stimulated for $5 \mathrm{~min}$ with $\mathrm{T}^{*} \mathrm{~m}$ (a) or by FceRI cross-linking $(\operatorname{IgE}+\mathrm{Ag} ; \mathbf{c})$. The levels of phosphorylated PKD, ERK, and p38 were analyzed by immunoblotting. b Densitometry of phosphorylated kinases in $\mathrm{T}^{*} \mathrm{~m}$-stimulated MC. d Densitometry of phosphorylated kinases in LAD2 cells stimulated by cross-linking the FceRI. Representative results from 5 independent experiments are shown. Max., maximum; pP38, phosphorylated p38.

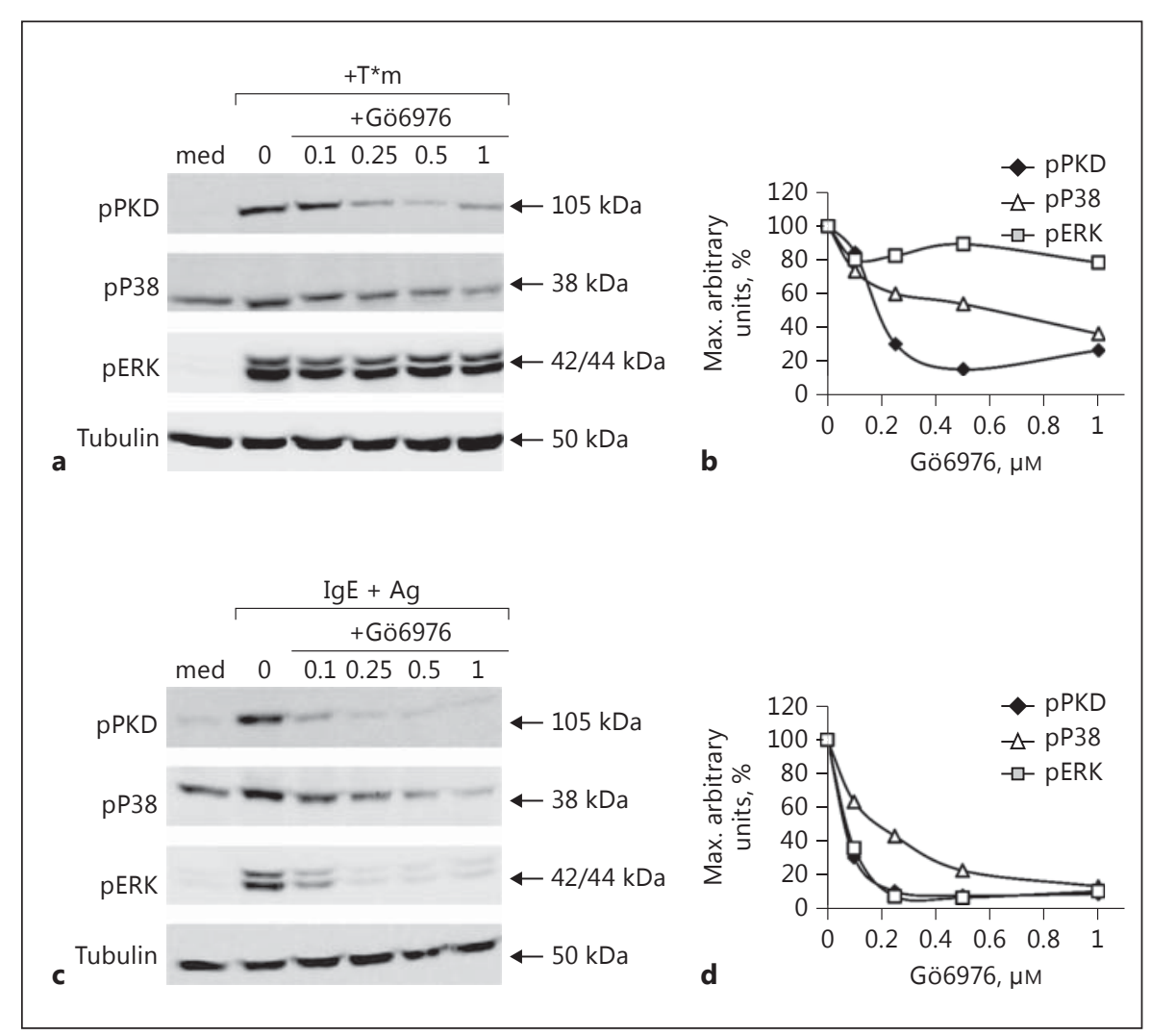

$\mathrm{pg} / \mathrm{mL}$, respectively). Thereafter, we explored whether $\mathrm{PKD}$ is involved in degranulation (by means of $\beta$-hexosaminidase release) and cytokine release. By using Gö6976, a significant dose-dependent inhibition of both $\beta$-hexosaminidase (Fig. 3b) and the 3 cytokines which were tested (Fig. 3c) could be observed, reaching maximal inhibitions of $70,75,76$ and $65 \%$ for $\beta$-hexosaminidase, CCL2/MCP1 and OSM, and IL-8, respectively. Taken together, these results indicate that $\mathrm{PKD}$ is involved in $\mathrm{T}^{*} \mathrm{~m}$-induced human MC degranulation and cytokine release.

\section{Discussion}

Recent studies have shown that heterotypic adhesion of MC to activated but not resting T cells induces MC degranulation and cytokine production in a pathway associated with the activation of Ras and the MAPK signaling pathway [1-5].

We now show that $\mathrm{T}$ cell-induced MC activation induces PKD activation as well. The LAD2 human MCline, as well as primary CBMC, express PKD protein constitutively, phosphorylated upon stimulation with $\mathrm{T}^{*} \mathrm{~m}$ but not with Tm, thus supporting the validity of LAD2 as a human MC model $[11,12]$. FceRI cross-linking stimulation of LAD2 human MC resulted in PKD phosphorylation as well (Fig. 1). Moreover, murine and rat MC were also found to constitutively express $\mathrm{PKD}$, which was activated in these cells upon stimulation through FceRI, the high-affinity receptor for IgE $[8,13]$. In contrast, in an untreated HMC-1 human MC line, a low basal level of phosphorylated PKD could be noticed [14]. This discrepancy between LAD2 and HMC-1 human MC lines could be due to differences in the phenotype of the cells, with the former exhibiting a more mature phenotype [6].

In naïve and Tm-stimulated LAD2 cells, $\mathrm{PKD}$ was distributed in the cytoplasm whereas upon stimulation with $\mathrm{T}^{*} \mathrm{~m}$, it partially translocated to the plasma membrane (Fig. 1d). This could be observed for a relatively long time period of $30 \mathrm{~min}$. However, in RBL $2 \mathrm{H} 3$ cells, stimulation via FceRI resulted in rapid transient redistribution of GFP-PKD from the cytosol to the plasma membrane and vice versa, within 10 min of antigen receptor engagement [9]. We also documented rapid PKD phosphorylation, which peaked at $5 \mathrm{~min}$, in human MC stimulated via FceRI. This discrepancy in PKD translocation could be 


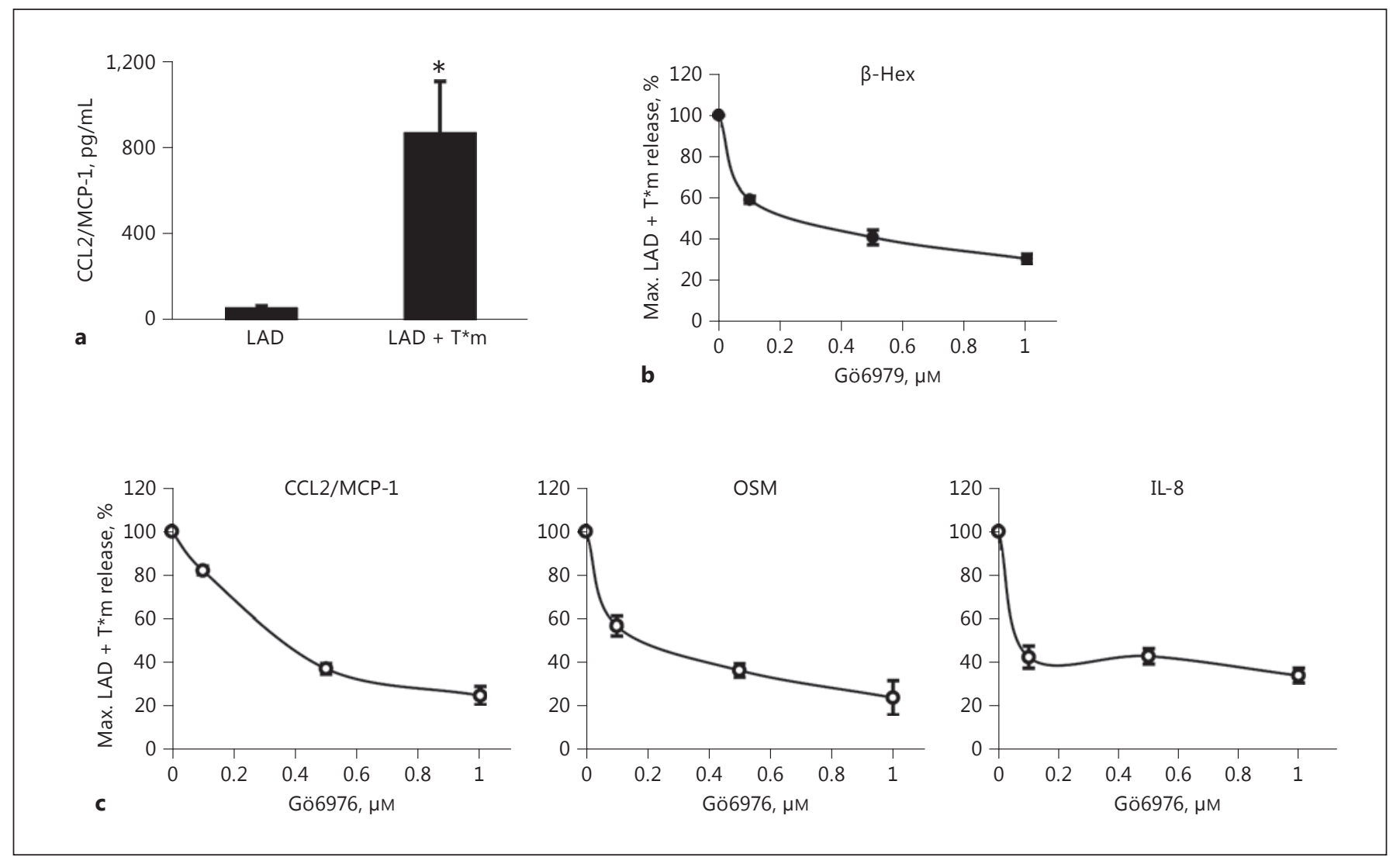

Fig. 3. The involvement of $\mathrm{PKD}$ in degranulation and cytokine release from human MC. a LAD2 cells were incubated with $\mathrm{T}^{*} \mathrm{~m}$ for overnight and CCL2/MCP-1 release was assayed by ELISA $(* p<$ $0.05)$. LAD2 cells were preincubated for $30 \mathrm{~min}$ with the indicated concentrations of Gö6976. Subsequently, cells were incubated with $\mathrm{T}^{*} \mathrm{~m}$ overnight. Supernatants were collected and analyzed for the measurement of $\beta$-hexosaminidase (b) or CCL2/MCP-1, OSM, and IL- 8 release $(\mathbf{c})$. Data are expressed as percentage of maximal secretion. Results are shown as mean \pm SE of 3 independent experiments done in duplicate. $\beta$-Hex, $\beta$-hexosaminidase; Max., maximum. explained by the different activation pathway which was used. While our human MC were activated by T cells, the murine MC were activated through FceRI cross-linking. Indeed, we have previously reported that activation of MC after contact with T cells induces an expression profile that is different from stimulation by FceRI cross-linking, resulting in a different pattern of mediator release. In particular, the cytokines IL-8, OSM, and IL-24 are uniquely secreted in the T cell-induced activation pathway [2-4].

Another difference between these 2 pathways of MC activation was noticed when we explored whether MAPKs are affected by PKD activation. While PKD phosphorylation in MC activated by T cells leads to the phosphorylation of p38, but not of ERK, activation of the cells by FceRI cross-linking leads to PKD phosphorylation that results in both p38 and ERK activation. Therefore, we can pos- tulate that in T cell-induced $\mathrm{MC}$ activation, $\mathrm{PKD}$ probably exerts its effects via p38, while in "classical" IgE receptor cross-linking, PKD influences both p38 and ERK MAPK. Indeed, a variation between these $2 \mathrm{MC}$ activation pathways was shown previously with regard to ERK activation. While activated T cells caused sustained ERK phosphorylation and IL- 8 release by human MC, FceRI cross-linking was followed by transient ERK activation and the preferential secretion of TNF- $\alpha$ [5].

PKD was found to exert its effect by using different MAPKs under various conditions. The involvement of PKD in activating p38 was found while exploring the TLR5 response to its ligand, flagellin, in the HEK 293T epithelial cell line. PKD mediated the phosphorylation of TLR5 in response to flagellin, which, in turn, contributed to the activation of the p38 and the release of IL- 8 . Fur- 
thermore, this PKD involvement in the p38-mediated IL-8 response to flagellin was inhibited by using Gö6976 [15]. PKD was also found to be involved in the activation of ERK. In differentiated primary mouse keratinocytes, PKD has served as a major regulator of a proliferative response, probably by causing prolonged ERK activity [16].

In this study, we also show that $\mathrm{PKD}$ is associated with the degranulation and release of several cytokines and chemokines from $\mathrm{T}^{*} \mathrm{~m}$-stimulated MC (Fig. 3), such as CCL2/ MCP-1, which is known to mediate the activation and recruitment of inflammatory cells and plays an important role in asthma [17]. CCL2/ MCP-1 production was also reported in BMMC activated by palmitoyl3-cysteine-serine-lysine- $4\left(\mathrm{Pam}_{3} \mathrm{CSK}_{4}\right), \mathrm{SCF}$ or FceRI cross-linking; however, in contrast to our findings, Murphy et al. [8] did not find PKD to be involved in degranulation. The usage of human versus murine $\mathrm{MC}$ and the diverse stimuli used could explain these contradictory results.
PKD can be activated in a PKC-dependent way or by other pathways independently of PKC [18]. Future work is required to address this issue in $\mathrm{T}^{*} \mathrm{~m}$-stimulated MC. In summary, we show for the first time that PKD is involved in T cell-induced MC activation. These findings may contribute to our understanding of the molecular events associated with this pathway of activation.

\section{Acknowledgments}

We thank F. Levi-Schaffer, PhD, Hebrew University Medical School, Jerusalem, for providing the CBMC. This work was supported by a grant from the Israel Science Foundation (to Y.A.M.) and Tel Aviv University. Y.A.M. is the incumbent of the Argentina Chair of Allergic Diseases, Tel Aviv University.

\section{Disclosure Statement}

All authors confirm that they have no conflict of interests in relation to this work.

\section{References}

1 Baram D, Vaday GG, Salamon P, Drucker I, Hershkoviz R, Mekori YA: Human mast cells release metalloproteinase- 9 on contact with activated $\mathrm{T}$ cells: juxtacrine regulation by TNF- $\alpha$. J Immunol 2001;167:4008-4016.

2 Salamon P, Shoham NG, Gavrieli R, Wolach B, Mekori YA: Human mast cells release interleukin-8 and induce neutrophil chemotaxis on contact with activated T cells. Allergy 2005;60:1316-1319.

3 Salamon P, Shoham NG, Puxeddu I, Paitan Y, Levi-Schaffer F, Mekori YA: Human mast cells release oncostatin $\mathrm{M}$ on contact with activated T cells: possible biologic relevance. J Allergy Clin Immunol 2008;121:448-455.

4 Shefler I, Pasmanik-Chor M, Kidron D, Mekori YA, Hershko AY: T cell-derived microvesicles induce mast cell production of IL-24: relevance to inflammatory skin diseases. J Allergy Clin Immunol 2014;133:217-224.e1-e3.

5 Mor A, Shefler I, Salamon P, Kloog Y, Mekori YA: Characterization of ERK activation in human mast cells stimulated by contact with T cells. Inflammation 2010;33:119-125.

6 Kirshenbaum AS, Akin C, Wu Y, Rottem M, Goff JP, Beaven MA, Rao VK, Metcalfe DD: Characterization of novel stem cell factor responsive human mast cell lines LAD 1 and 2 established from a patient with mast cell sar- coma/leukemia; activation following aggregation of FcepsilonRI or FcgammaRI. Leuk Res 2003;27:677-682.

7 Rykx A, De Kimpe L, Mikhalap S, Vantus T, Seufferlein T, Vandenheede JR, Van Lint J: Protein kinase D: a family affair. FEBS Lett 2003;546:81-86.

8 Murphy TR, Legere HJ 3rd, Katz HR: Activation of protein kinase D1 in mast cells in response to innate, adaptive, and growth factor signals. J Immunol 2007;179:7876-7882.

9 Matthews SA, Iglesias T, Rozengurt E, Cantrell D: Spatial and temporal regulation of protein kinase D (PKD). EMBO J 2000;19: 2935-2945.

10 Gschwendt M, Dieterich S, Rennecke J, Kittstein W, Mueller HJ, Johannes FJ: Inhibition of protein kinase $\mathrm{C}$ mu by various inhibitors. Differentiation from protein kinase $\mathrm{C}$ isoenzymes. FEBS Lett 1996;392:77-80.

11 Kirshenbaum AS, Petrik A, Walsh R, Kirby TL, Vepa S, Wangsa D, Ried T, Metcalfe DD: A ten-year retrospective analysis of the distribution, use and phenotypic characteristics of the LAD2 human mast cell line. Int Arch Allergy Immunol 2014;164:265-270.

12 Kratzer B, Pickl WF: Years in review: recent progress in cellular allergology. Int Arch Allergy Immunol 2016;169:1-12.
13 Matthews SA, Rozengurt E, Cantrell D: Protein kinase D: A selective target for antigen receptors and a downstream target for protein kinase C in lymphocytes. J Exp Med 2000;191: 2075-2082.

14 Kandere-Grzybowska K, Kempuraj D, Cao J, Cetrulo CL, Theoharides TC: Regulation of IL-1-induced selective IL-6 release from human mast cells and inhibition by quercetin. $\mathrm{Br}$ J Pharmacol 2006; 148:208-215.

15 Ivison SM, Graham NR, Bernales CQ, Kifayet A, Ng N, Shobab LA, Steiner TS: Protein kinase $\mathrm{D}$ interaction with TLR5 is required for inflammatory signaling in response to bacterial flagellin. J Immunol 2007;178:5735-5743.

16 Jadali A, Ghazizadeh S: Protein kinase D is implicated in the reversible commitment to differentiation in primary cultures of mouse keratinocytes. J Biol Chem 2010;285:2338723397.

17 Wang A, Wang Z, Cao Y, Cheng S, Chen H, Bunjhoo H, Xie J, Wang C, Xu Y, Xiong W: CCL2/CCR2-dependent recruitment of Th17 cells but not Tc17 cells to the lung in a murine asthma model. Int Arch Allergy Immunol 2015;166:52-62.

18 Wang QJ: PKD at the crossroads of DAG and PKC signaling. Trends Pharmacol Sci 2006; $27: 317-323$. 